\title{
LA SEMIÓTICA Y LA EDICIÓN DE UN TEXTO POÉTICO INTEGRAL
}

\author{
Rodica Marian
}

Instituto de Lingüística e Historia Literaria «Sextil Puscariu» (Cluj-Napoca)

1.1. La impresión del texto poético integral de Luceafărul (El lucero) ${ }^{*}$, con la reedición de las variantes en una nueva forma, basada, en principio, en la lectura e interpretación de los manuscritos de la edición Perpessicius (Eminescu, 1943: 370-455) se convierte en una tarea cultural absolutamente necesaria desde la perspectiva de la investigación moderna del texto poético, tanto más si el volumen de la edición académica en el que se encuentran estas variantes es bastante difícil de encontrar, ya que el tomo data de 1943. Y más todavía, si tenemos en cuenta que el texto más analizado de la literatura rumana, el poema Luceafărul, no ha sido todavía, más que esporádicamente ${ }^{1}$, interpre-

* N.T. En la edición políglota de Z. Dumitrescu-Busuleanga (Bucarest, Editura Albatros, s.f.) el título escogido por María Teresa León y Rafael Alberti para la versión española es Hiperión.

1 En algunos capítulos del análisis semántico de nuestro libro «Los mundos» de Luceafärul, como serían los capítulos: IV, V, VI, VII, VIII; XII, XV, se hace referencia al texto integral del poema. 
tado como un texto integral, englobando el texto definitivo, variantes, y borradores que presentan una conexión semántica (Marian, 1999a). Por lo tanto creemos que la edición que hemos pensado y realizado (Marian, 1999b) será bien acogida por los amantes de la poesía de Eminescu, ya que pone a su disposición el material poético de los manuscritos, con una nueva ordenación y puesta en página de los versos y de las variantes de Luceafărul, al lado del texto definitivo publicado por el poeta y de las poesías líricas póstumas resultadas de la atmósfera del gran poema (éstas últimas, llamadas por Perpessicius «poesías colaterales» y que han sido reproducidas en el Anexo de nuestra edición). Todo ello está encaminado a dar a conocer la obra maestra de Eminescu, el laboratorio mismo de creación del poeta, del cual va a resultar el fondo ideático y filosófico del poema, sorprendentemente explícito en versión genuina.

Nuestra edición responde, en primer lugar, a la necesidad de establecer un texto poético integral de Luceafărul (el texto definitivo y las variantes), del que se ha establecido una lista de palabras poéticas, recogidas y definidas en el primer Diccionario de «Luceafărul» eminesciano (Marian y Șerban, 2000). Así, los valores semántico-poéticos del vocabulario integral, entre los cuales se van a establecer correlaciones y correspondencias intratextuales van a ser capaces de aclarar de otra manera el sentido global simbólico del gran poema y reevaluar muchas opiniones exegetas de la gigantesca literatura sobre Luceafărul, integradas en la mayoría de los casos en una óptica reductora, tradicionalmente romántica.

1.2. Por su naturaleza, la disciplina de la edición de textos como dirección analítica es una actividad filológica destinada a asegurar el establecimiento del texto auténtico «a través de una crítica de los textos, es decir, a través del examen atento de todas las particularidades de texto, gráficas y linguísticas» (Ghetie y Mares, 1974:10). Tal y como Carmen Vlad ha observado, con razón, aunque la finalidad de la actividad filológica difiera de la del análisis textual, concebido dentro de un sistema semiótico complejo, «los métodos utilizados, al igual que una parte de los resultados obtenidos, coinciden. En ambos casos interesa el conocimiento o el restablecimiento de las condiciones reales de la situación comunicativa (el emisor $=$ el autor, el lugar $=$ el momento de la producción del texto) por o junto con la descripción lingüística del texto» (Vlad, 1982: 85). Para precisar el lugar que ocuparía la edición de un texto en el marco de una semiótica, debemos apelar a la noción de semiótica específica, tal y como ha sido comprendida por 
Sanda Golopentia-Eretescu (1978: 3-17), en el sentido de semiótica particular posible en el futuro de la semiótica, tal y como lo veía la investigadora en el momento de la producción de su estudio. Operando con cinco distinciones cruciales, entre las cuales, la primera, la distinción entre teoría y aplicación es decisiva, la autora citada pone de manifiesto nuevas relaciones entre los tres factores de la semiosis: signos, objetos y los utilizadores de signos, y postula luego, entre otros, varios tipos de semiótica con ámbitos homogéneo y heterogéneo. Lo que nos parece importante es que, desde nuestro punto de vista, en la clasificación general de las operaciones semióticas, aparece entre los subtipos el de las aplicaciones interaccionales, llamadas estrategias, con respecto a las cuales se precisa que «no se pueden formar más que sobre una teoría pragmática, ya que sólo en una teoría pragmática se tiene en cuenta una clase de agentes: los utilizadores de signos» (Golopenția-Eretescu, 1978: 11).

1.3. La edición de textos, y sobre todo el establecimiento de un texto integral, se puede englobar, en nuestra opinión, en estas estrategias, y la teoría pragmática sobre la que se forma esta disciplina filológica puede ser una pragmática heterogénea, en acepción tipológica, porque aborda al menos dos grupos de signos, al menos dos grupos de objetos y al menos dos grupos de utilizadores de signos. Según Sanda Golopentia-Eretescu, la pragmática heterogénea se enmarca evidentemente dentro de una semiótica heterogénea, guardando y ampliando la distinción entre sintaxis, semántica y pragmática, introducida por Charles Morris, desde 1938, en la metateoría semiótica. Por lo tanto, en la sintaxis de la semiótica heterogénea se encuentran sólo las relaciones entre los signos, a nivel de dos grupos o de varios, en la semántica de la semiótica heterogénea hay dos o varios grupos de signos y dos o varios grupos de objetos, mientras que en la pragmática heterogénea del objeto de la sintaxis y de la semántica se le añaden dos o varios grupos de utilizadores de signos. Hablando de los componentes tradicionales de la semiótica, la autora citada destaca que en la teoría de Morris «la pragmática es lo mismo que la semiótica global, es la forma máxima de la semiótica» (Golopentia-Eretescu, 1978: 7). La afirmación es sorprendente, sobre todo porque ella no viene de un adepto de la pragmática integrada, disciplina que no tiene más que los componentes linguiística y retórica (Ducrot, 1984) y se opone a unas consideraciones modernas sobre esta tradición. Entre las definiciones clásicas de los tres componentes de la semiótica, un diccionario específico más reciente (Moeschler y Reboul, 1999: 30) incluye también las contribuciones de unos filósofos del lenguaje como 
Peirce o Carnap, al lado de Morris, clasificándolas dentro del tipo de teoría pragmática lineal, ya que el orden del tratamiento sintaxis, semántica, pragmática es fundamental; las salidas de la pragmática sólo describen el valor de acción del enunciado. Los autores del diccionario mencionado explican, por otra parte, por qué hoy la pragmática no se puede enmarcar en la semántica o en la semiótica, dado que «los procesos descritos por la pragmática actúan sobre unas informaciones extremadamente diferentes que no son obligatoriamente lingüísticas» (Moeschler y Reboul, 1999: 479).

En cuanto a nuestro estudio, aceptaremos, por lo tanto, los parámetros metateóricos de lo que hemos definido más arriba como pragmática heterogénea. Nos parece evidente que el establecimiento de un texto integral se sitúa en una semiótica heterogénea, al tratarse de varios textos que deben ser puestos en una conexión semántica, es decir, las distintas versiones y variantes manuscritas deben ser relacionadas con el texto definitivo, bajo una relación sintáctica y semántica. En cuanto a los grupos de utilizadores de signos son más de dos, en este caso particular del texto integral de Luceafărul.

El correcto conocimiento de los aspectos pragmáticos es esencial, como dice Carmen Vlad, para la comprensión y/o la interpretación del fenómeno textual, «incluso en las condiciones en las que la óptica interpretativa es una exclusivamente lingüística» (Vlad, 1982: 83), porque el texto como producto es el resultado de un contexto cultural específico, localizado en el espacio y en el tiempo. La interpretación pragmática incluye por consiguiente el nivel del conocimiento de las condiciones reales de la producción del texto (en el caso de Luceafărul, la datación y la ubicación de las seis versiones, como etapas distintas de la génesis del poema, al igual que las del texto definitivo, seguido luego de la versión Maiorescu, con sus propias condiciones y determinaciones pragmáticas, problemas que vamos a tratar puntualmente más adelante, en el párrafo 2.3.). En el aspecto pragmático entra también la condición espacio-temporal del utilizador de signos, que es en nuestro caso Perpessicius, el editor más competente de los manuscritos de Eminescu, al igual que los utilizadores, que son sus predecesores, corregidos o aceptados parcialmente, junto con la concepción y la finalidad perseguida por estas ediciones. Otro grupo de utilizadores, con sus propias determinaciones y con la visión específica, se configura a través de las intenciones de nuestra edición, de las exigencias de lo que hemos llamado el restablecimiento de un texto poético integral. 
1.4. Antes de exponer las motivaciones que nos llevaron a reelaborar la edición Perpessicius, y antes de hacer referencia a la necesidad de reordenar semánticamente el material poético de las variantes en otra puesta en página, de tal manera que el lector pueda detectar más fácilmente las innovaciones, modificaciones o cambios de la expresión, vamos a mostrar que de esta reordenación del texto de las variantes se va a constituir lo que llamamos «el texto poético integral» del poema Luceafărul. Aplicando los términos de Schmidt (1973: 150) y las consideraciones vinculadas con el intertexto, Alexandru Niculescu intenta una definición más amplia del texto poético: «Consideramos texto poético todas las hipóstasis del proceso de constitución de la textualidad con función estética. Un texto poético engloba por lo tanto manuscritos, "submanuscritos", fragmentos, variantes y "borradores" en una conexión semántica, jerárquica y temporalmente organizada. [...] El texto "ideal" se encuentra implicado en cada intento de elaboración poética, desde la primera variante hasta el texto último (s. n., R. M.)» (Niculescu, 1980: 143-144). El texto poético integral tiene, por consiguiente, una estructura de profundidad común e idéntica tanto para las variantes (en la terminología de los teóricos franceses, avant texte), como para el texto publicado por el poeta. Es más, los constituyentes del texto definitivo (los lexemas, las construcciones sintagmáticas, las unidades de frase, etc.), que se pueden volver a encontrar también en las variantes, aseguran lo que hemos señalado en el contexto como conexión semántica. Vamos a añadir solamente que entendemos el texto poético integral de forma concreta, como un texto continuo, desde la primera versión hasta la impresa durante la vida del poeta y no de forma «ideal», en el sentido de que en esta totalidad se puede encontrar la estructura profunda del texto, la misma para las variantes, como para el texto definitivo.

1.5. La edición del texto integral de Luceafărul hace posible, por primera vez, el estudio del vocabulario específico de los intertextos, término que comprendemos como textos de las cuatro versiones manuscritas distintas y de las dos versiones impresas (con sus variantes, a veces muy numerosas) que se han constituido como formas finales en cierto momento de la génesis del poema. Estas versiones marcan y explican «la textualidad» del texto integral. Conviene precisar, en este orden de ideas, que estamos de acuerdo con las consideraciones y las delimitaciones recientes de Carmen Vlad acerca de las cinco categorías de la transtextualidad en G. Genette, en el sentido de que el fenómeno de la transtextualidad como aspecto de la textualidad es una característica general textual (Vlad, 2000: 61) y no exclusivamente objeto de la 
poética. La hipertextualidad, tal y como ha sido definida por G. Genette (1982: 11-13), puede tener contactos con lo que pasa en el proceso de la constitución de un texto integral, porque esta categoría representa una relación de un texto con uno anterior, sobre el cual se sobrepone. Pero, en esta definición, el segundo texto deriva del primero por transformación o por imitación, puesto que se trata de textos apenas relacionados, a veces sin tener nada que ver, mientras que los textos de las versiones sucesivas de un texto integral están más cerca los unos de los otros. Por otra parte, tal y como ha observado Carmen Vlad, la hipertextualidad no puede evitar acercarse demasiado a la intertextualidad, de modo que esta última categoría puede englobar a la primera. Lo que podemos retomar de la categoría genérica de la transtextualidad es precisamente la idea de que ésta es «todo lo que pone al [texto] en relación evidente o secreta con otros textos», según Genette, precisando que estos otros textos son, en el caso de la reconstitución del texto integral, los textos mismos de las variantes anteriores al texto definitivo.

1.5.1. Si tuviéramos que situar la edición de texto (integral) dentro de la relación específica de la lectura, podríamos decir que el editor puede ser el lector más cercano al creador, en el sentido de que a él también se le ofrece, como decía Valéry a propósito del autor, una pluralidad de vías durante el trabajo de producción (Valéry, 1938: 42), y la relación entre el editor y la obra, al igual que la que hay entre el lector y la obra, a la que se refiere Irina Mavrodin (1982: 14), puede ser vista como objeto de una poiética «que se interferiría con el ámbito de la pragmática, pero no coincidiría con éste, ya que éste último estudia prioritariamente el modo en el que los mecanismos de la recepción están bajo la incidencia de unos consensos sociales». Por consiguiente, la poiética del editor refleja siempre algo de las condiciones socioculturales de la época, y el proceso dinámico entre poiética y poética, propio del trabajo del editor, se somete a una doble restricción: primero la del conocimiento y de la reconstitución de las condiciones pragmáticas de la producción de la obra propiamente dicha, y luego debe percibir lo más correctamente posible el horizonte de expectativas de la recepción particular de su época, es decir, aquella determinación inscrita, según nuestra opinión, en las diversas etapas de la valorización de las grandes herencias de los clásicos. Creemos que es también el caso de Eminescu, hoy sensiblemente disputado incluso en Rumanía, precisamente porque, desde hace más de un siglo, se ha generalizado su simplificadora catalogación de romántico tardío, que por supuesto ya no cuadra con la sensibilidad actual. La eminescología actual, muy diversa y prolífica, no ha cambiado nada todavía a la 
imagen reductora del poeta romántico y pesimista y no ha cambiado tampoco el lugar común que sitúa a Eminescu en el siglo XIX. Sin embargo es verdad, como se ha dicho (Neț, 1992: 242), que en el ámbito de las mentalidades, dominado por las resistencias, el cambio de la costumbre es difícil de percibir. Así, resulta paradójico que las ideas del texto integral de Luceafărul, sin ser todavía conocidas por la mayoría del público, y sin ser impuestas como mentalidad, no cuadran con una de las apetencias de la época actual, que es la resurrección misma de los valores filosóficos del Extremo Oriente, aunque el fundamento del pensamiento profundamente arraigado en el poema, esté bajo el signo de unas confluencias con la mentalidad india. Estas correlaciones han sido y son a menudo puestas de manifiesto en las investigaciones sobre la obra de Eminescu, verdad intuida también por Lucian Blaga (1968: 20), que menciona que Eminescu ha presentido «una secreta afinidad entre el fondo de los dacios y la modalidad del espíritu índico».

1.6. Una presentación del laboratorio de creación de Eminescu puede interesar a cualquier amante de la poesía del autor, a quien $\mathbf{N}$. Iorga ha definido, desde 1929, como «la expresión integral del alma rumana» (Perpessicius, 1989: 138) y es a Iorga también a quien debemos la sentencia «nada de lo que Eminescu haya escrito es falto de interés». La investigación y la edición de las variantes de Luceafărul se vuelven instructivas en muchos aspectos, entre los cuales el pragmático es esencial, como decíamos, condensando un trabajo excepcional, a medida del valor del poema. Se reconoce, en general, el carácter representativo de Luceafărul para la obra del poeta: «Si desaparecieran todas las poesías de Eminescu, se podría reconstituir su personalidad, su lírica erótica, metafísica, sus obsesiones esenciales, sólo a partir de Luceafărul» (Constantinescu, 1987: 250). Son suficientes razones que subrayan la importancia de conocer los manuscritos para el estudio del texto poético definitivo, que debe descifrar también los secretos del sentido poético, con su variedad de valencias. Es lo que Maria Corti considera il viaggio testuale, viaje por medio del cual el lector puede entrar en el texto y recorrerlo hacia innumerables direcciones (Corti, 1978). Sintetizando, vamos a señalar, junto con Alexandru Niculescu, la idea de que, en busca del núcleo de ideas profundo del poema, cualquier manuscrito, submanuscrito o borrador «es un indicio necesario y valioso. Un viaje al interior de un texto poético significa también una implicación del texto en la cultura, en la historia, en la sociedad» (Niculescu, 1980: 144). Lo que significa que el texto integral puede acceder a la reconstitución correcta de una imagen general, tanto del 
contexto cultural en el que se ha producido la obra, como también del contexto personal del autor, reflejando su intención y la estructura de su personalidad.

1.7. Por consiguiente, todos los elementos contenidos por las variantes cobran importancia para comprender el gigantesco esfuerzo realizado por Eminescu en su conocida lucha con la forma, al intentar llevar el lenguaje poético a las cuotas de su sensibilidad musical y de hacer que éste abarque toda su imaginación. Eminescu, bien se sabe, estaba siempre buscando la palabra «que expresa la verdad», consciente de las dificultades en encontrarla (Cînd cu sete cauti forma ce să poată să te-ncapă «o» Cînd pe mine forma, limba abia poate să mă - ncapă). Por eso, el constante interés mostrado por ciertos conceptos, en los que trabaja detenidamente, desvela aquellos centros de la poeticidad de los que hablaba Alexandru Niculescu.

El análisis del texto integral va a acceder al refinamiento eurístico de la así llamada lectura temática, ella misma consecuencia de la lectura de las versiones y de las variantes del poema. La lectura temática, posible por la inclusión de varias lecturas de la expresión lingüística, tanto de las variantes como del texto definitivo, conduce también a una redefinición del objeto llamado texto poético, que debe ser comprendido como un continuum de variantes, versiones, borradores, todos relacionados por abarcar el mismo tema.

Hace unos cuantos decenios, algunas teorías poéticas han planteado insistentemente el problema del texto poético como proceso de elaboración, como un trabajo permanente, móvil y continuo, cuya última fase es, obligatoriamente, el poema en su forma final. Paul Valéry (Cimpoi, 1999: 61) concebía la variante como una forma de manifestación de las profundidades, íntimamente relacionada con la idea de que el poema no está nunca terminado, y su forma definitiva se debe a un simple accidente, a un acontecimiento fortuito. El mismo Valéry hablaba también de una «intencionalidad» del hacer del poema, en el sentido de que la elección que implica en cada momento la actividad creadora se sitúa a menudo «fuera de la creación misma», y los efectos divergentes, posibles y legítimos de la obra corresponden a la pluralidad de vías que se le han ofrecido al autor durante la creación (Valéry, 1938: 32, 42), lo que en los términos de la poiética moderna (Mavrodin, 1982: 70-71) puede significar no solamente un intento de teorizar la lectura plural a través de la perspectiva de la poiética, sino también la inclusión en el proceso poiética/poética de la pluralidad de los intentos materializados en variantes. También se ha discutido 
detenidamente el problema de la relación entre texto y avant texte, como denomina Bellemin Nöel (1972) el conjunto de variantes independientes, y el análisis poético significa interceptar direcciones de desarrollo del sentido poético, según C. Contini (1970). La incorporación sucesiva de las variantes en un texto debe ser seguida para poder captar y realizar el texto último, señala Alexandru Niculescu, y por otra parte, «siguiendo las variantes, comprendemos lo que el escritor ha transpuesto en la obra, pero también lo que él ha dejado sin voz, virtualidades que no han llegado a materializarse pero que tienen valor para su comprensión» (Niculescu, 1980: 139). Así, la estrategia de la edición es al mismo tiempo una interpretación, que puede acceder a una clarificación de los conceptos poéticos de la obra, recompuesta de la semántica heterogénea de las versiones independientes, al lado de la puesta en evidencia de los vínculos entre signos, es decir, una sintaxis heterogénea que interviene entre lo que aparece y lo que no aparece en el texto último; este proceso es revelador no sólo para definir a un poeta, sino también para definir un texto, como el de la obra maestra de la literatura rumana, el poema Luceafărul, cuya génesis es una auténtica historia.

1.8. Al examinar atentamente las versiones y las variantes sucesivas del proceso de creación de Luceafărul, vamos a descubrir aquellos elementos que satisfacen o no las exigencias del poeta, transformaciones y no transformaciones, correcciones de la construcción del poema, modificaciones de las relaciones entre los elementos, eliminaciones y reintegraciones, en fin, aquellas formas que han sido abandonadas en «la noche de los manuscritos». El estudio de éstos es especialmente útil, como lo demostraba Perpessicius en 1937, para colocar las discusiones «en el corazón mismo de la creación y de sus múltiples secretos» (Perpessicius, 1989: 24). La preferencia por el valor poético de las variantes, de las póstumas de Eminescu en general, es evidente también en otro gran editor, Petru Cretia, que ha continuado el laborioso trabajo de Perpessicius. La idea de que Eminescu no tenía una conciencia crítica adecuada a su propio valor y que las publicaciones hechas durante la vida, con su perfecta forma esculpida, son inferiores al esplendor único y a un lirismo frustrado y de auténtico impulso visionario de los manuscritos, ha sido sostenida también por I. Negoitescu, pero Petru Creția observa además el hecho de que los tesoros de poesía que han sido recuperados por la publicación de los manuscritos se los debemos a la instancia crítica que representa «la tradición de una cultura orgánica, equilibrada y lúcida, que ha dominado la voluntad [del poeta]: a través de Maiorescu, de los editores de las póstumas de principios de 
siglo, a través de Cãlinescu, de Perpessicius y sus seguidores, de Negoitescu, de Iorga» (Creția, 1991: 17).

Por otra parte, la integralidad de las versiones del poema Luceafărul tiene la ventaja de poder recuperar algo de la intención del autor, cercana a la estructura de profundidad del proyecto del que ha nacido el poema, proyecto al que la estrategia de la edición debe hacer perceptible. Existe, como se ha dicho, siguiendo los términos de la estilística del autor, un «etimón espiritual» de cada obra, según la conocida expresión de Leo Spitzer, o, como lo muestra recientemente Ion Coteanu, un núcleo referencial que «contiene la totalidad de los elementos implicados en la acción de imaginar el mundo del texto» (Coteanu, 1985: 28). Nos parece interesante que Eminescu, en un artículo de juventud, intuyera una verdad parecida hablando de la necesidad de que la poesía codificara una idea poética: «La idea es el alma y este alma lleva ya dentro como inherente el pensar de su cuerpo» (Eminescu, 1977: XX). El texto integral de un poema puede informarnos sobre su autor, partiendo de lo que el poeta ha entrevisto, porque, tal y como lo ha demostrado A. Niculescu en el estudio citado (1980: 144) «el texto último no puede contener más que los resultados: los avant textes completan la imagen poética, presentando los esfuerzos, los intentos, los avatares de la creación. Esto ayuda en la reconstrucción de lo que la exégesis llama Formgeschichte». Por lo tanto, vista desde una perspectiva semiótica, la constatación de estas ventajas apoya nuestra idea de que la estrategia de reconstrucción implicada en la edición del texto integral debe tener en cuenta el destino de éste, que, en última instancia, es la puesta en evidencia misma de los sentidos escondidos del poema, es decir, en otras palabras, según la expresión de Eminescu, debe descifrar lo que el poeta ha codificado deliberadamente en los símbolos de la poesía.

2.1. Al editar los manuscritos, surge el problema de su ordenación (incluyendo también lo que Perpessicius llamaba «submanuscritos»), en función del descubrimiento de las relaciones de continuidad entre las variantes, operación que supone, a su vez, la puesta en evidencia de los elementos comunes de una versión a otra. Desde un punto de vista semiótico, esta interacción supone una sintaxis, cercana a la heterogeneidad de las relaciones entre los signos de cada versión. De la misma manera, a través de la estrategia de la edición se van a seguir las relaciones semánticas entre los signos de cada versión o variante y lo que hemos definido más arriba como núcleo referencial del poema, etimón espiritual o idea poética codificada. A lo largo de esta interacción, que tiene supuestamente la finalidad de aproximar el símbolo poético 
global del poema, la puesta en evidencia de los centros de poeticidad se va a constituir como una especie de red de nudos del texto integral, marcando el contorno de los temas mayores del texto poético, por la insistencia del poeta que los trabaja insistentemente, en innumerables variantes, formas de expresión, en distintos co-textos y asociaciones semánticas. Su aparición en el fluir del texto integral advierte sobre la importancia, a veces obsesiva, con la que la imaginación creadora de Eminescu ha intentado trasladar, en el plano de la expresión, los conceptos — clave del poema-.

En la edición de Perpessicius, las versiones de Luceafărul, han sido establecidas también en base a los criterios de continuidad de las etapas de creación del poema, mientras que la edición del texto integral, entendido por nosotros como un continuum, desde la primera versión manuscrita hasta la edición de Maiorescu, está destinada a redescubrir los elementos comunes de las variantes (palabras, sintagmas o incluso estrofas) que aseguran la coherencia del texto poético y permiten su inclusión como variantes del mismo poema. Por consiguiente, los elementos comunes aseguran la pertenencia de las versiones y las variantes al mismo poema. Hay sin embargo casos controvertidos, como sería el de las poesías póstumas: Dacă iubești fără să speri, Și oare tot n-ai înteles..., Să fie sara-n asfințit, Un farmec trist și ne- nțeles, juzgadas por Perpessicius como pertenecientes a la constelación de Luceafărul, y consideradas por otros editores como variantes y preludios líricos del gran poema. Hemos recogido en el Anexo de nuestra edición referencias y argumentos a estas póstumas así como estos mismos textos.

2.2. Aunque «el despojarse de los adornos», fenómeno apuntado por G. Ibrăileanu y analizado atentamente por T. Vianu, ha significado un progreso en la exigencia de la forma y en el filtro de la estilización poética eminesciana, la recuperación en el texto integral de aquellas formas brutas, origen del lirismo de las profundidades, con sus conceptos y elementos expresivos, incorporando a veces la sensibilidad más pura, puede ser un esfuerzo recuperador y compensatorio en el sentido subrayado por las opiniones de I. Negoitescu (1980: 17-18). El crítico analiza el trabajo de Eminescu hacia una forma cada vez más sobria, despojada de lirismo y demuestra que las formas perfectas publicadas en vida son inferiores, a menudo, a la ternura y al lirismo puro de las póstumas. Así se va a poder comparar el tono original de la poesía de Eminescu y las potencias líricas de las póstumas, aquí variantes del poema, con las formas resultantes de la modelación estilística, por selección y eliminación de lo sobrante. Las formas per- 
fectas publicadas en vida, con el nivel aforístico de unas metáforas y símbolos, no tienen siempre el esplendor único de algunas variantes. Al considerar que la originalidad de la poesía de Eminescu no se percibe únicamente en el refinamiento estilístico y despersonalizado de la lírica correspondiente a lo publicado en vida, refinamiento tan alabado $^{2}$, y que las póstumas, generalmente, están todavía abiertas a investigaciones que valoricen de modo ejemplar sus potencias líricas y de ideas, abogamos por la importancia del estudio de las variantes del poema Luceafărul.

2.3. En cuanto al valor de las variantes, George Ușcătescu parte de la plenitud ontológica de la poética de Eminescu, y subraya, naturalmente, la importancia de su significación para la comprensión del poema definitivo: «Una cosa es la "génesis" y la "historia" del proceso creador de la poesía de Eminescu en su titánica lucha por obtener formas poéticas válidas para la eternidad del Verbo rumano y otra cosa es la cuestión de la fórmula superior lograda, que nuestra misma sensibilidad expresiva prefiere y elige sin vacilar, aún cuando se trate [...] de una "variante", quizá no la última en la cronología» (Ușcătescu, 1968: 13). Desde nuestro punto de vista, una formulación de variantes puede ser significativa en sentido pleno, no sólo bajo el aspecto de la expresividad, sino incluso para desvelar el pensamiento profundo, la estructura mental que genera ideológicamente el poema. La célebre estrofa final del poema definitivo: Trăind în cercul vostru strîmt/Norocul vă petre$c e, / C i$ eu, în lumea mea mă simt/Nemuritor și rece ${ }^{3}$ no se había perfilado todavía en las primeras dos versiones manuscritas del poema; en la primera ni siquiera aparecía la escena del bosque, pero el final de la versión original nos parece de lo más importante, porque se separa evidentemente de la tradicional interpretación romántica del genio no comprendido: Și se așază iar pe cer/Lucind singurătății (Y se posó de nuevo en el cielo/Brillando a la soledad).

Estos dos versos aparecen bruscamente, sin ninguna relación con el resto del texto de la versión. La palabra singurătate (soledad) persiste

2 Entre los eruditas investigadores extranjeros de la obra de Eminescu que han analizado el proceso de refinamiento estilístico tan característico de la creación Eminescu, véase Alain Guillermou, La Génèse intérieure des poésies d'Eminescu, 1963; L. Gáldi, Stilul poetic al lui Mihail Eminescu, 1965. Entre los numerosos estudios de Gh. Bulgãr que tratan este problema, recordamos aquí el trabajo M. Eminescu-Coordonate istorice si stilistice ale creației, 1980.

3 «Viviendo en vuestro estrecho círculo,/os persigue la muerte,/mientras yo existo aquí en mi mundo/helado e inmortal» (Traducción de María Teresa León y Rafael Alberti en la edición citada) (N.T.) 
luego en la segunda versión, en la que la réplica no verbalizada del Luceafăr a la última invocación de Cătălina tiene la siguiente expresión: Iar el în cearcăn luminos/Lucea cu bunătate/Și rece se uita în jos/L-acea singurătate/Dar nu mai cade ca- $n$ trecut [...]....(Mientras él, en halo de luz/Brillaba con bondad/Y frío miraba hacia abajo/Hacia esa soledad/Pero ya no cae como en el pasado). La subvariante de la estrofa penúltima de la misma versión mantiene el acento en la serenidad de la respuesta: Iar el surîde luminos/[...]/Și —nseninat se uită- $n$ jos/Lucind singurãtãții (Pero él sonríe luminoso/Y sereno mira hacia abajo/Brillando a la soledad). La intuición fundamental, la primera expresada en el complejo proceso de la formación del texto, por los dos versos aislados de la versión genuina (Și se așază iar pe cer/Lucind singurătătii), vuelve ahora matizada por el sentimiento sereno de quien miraba con bondad hacia la soledad de abajo. Lo esencial está contenido en las últimas palabras: Lucind singurătătiii, siendo el centro mismo del final, al igual que D. Caracostea decía de la sed de reposo, sintagma que lleva el acento más significativo de la gran oración del Luceafär, la sed de reposo siendo allí «el corazón mismo de la solicitud» (Caracostea, 1987: 154). Es evidente, por lo tanto, que el sentimiento trágico de la soledad no puede ser sólo una prefiguración de la soledad astral del héroe titular del poema, como cree A Guillermou (1977: 382), sino que se refiere a la suerte de los destinatarios de la luz del astro. Se prefigura, así, desde los co-textos hasta el poema definitivo, una interpretación semántica muy distinta de la tradicional y de todas las anteriores para el sentido textual del lexema singurătate, ya que hasta ahora no se había percibido el sentido figurado, el símbolo y/o la personificación que traslada la soledad de los seres humanos a la soledad del mar o a las soledades de las olas en movimiento (Marian y Șerban, 2000) ${ }^{4}$. Por supuesto, tal y como pensaba Eminescu, la codificación de la idea poética es más que evidente en el poema definitivo, y la lectura del texto integral hace posible precisamente el descifrar de ésta.

Tales ejemplos (véanse los archilexemas muerte, no vivencia, sentir, palabra, las construcciones poéticas el pesar de la negra nada, círculo estrecho, mi mundo, el silencio del mar etc.) de clasificación diferente o muy matizada en comparación con las definiciones contenidas en un anterior y riguroso Dictionar al limbajului poetic eminescian

4 Vean nuestros comentarios del estudio «Conceptul poetic de text integral», en Rodica Marian y Felicia Șerban (2000: 24-26), Dictionarul Luceafärului eminescian, y las definiciones de la palabra soledad en el diccionario. 
(1968) han sido posibles sólo a partir de la reconstitución del texto integral del poema Luceafărul.

2.4. Tal y como lo señalábamos en el intento de teorizar semióticamente la edición de un texto integral, sobre todo uno de la complejidad y amplitud del texto poético de Luceafărul (en versión genuina el discurso del demiurgo tiene más de 100 estrofas), la estrategia y/o la interpretación pragmática contiene necesariamente el conocimiento de las condiciones reales de la producción del texto. La recepción crítica y la valorización de las etapas de la creación del poema Luceafărul han tenido un destino tan especial como la evolución perturbada de su exégesis, que desde hace más de 120 años asalta, desde distintas perspectivas, el secreto de este seductor poema.

Si tuviéramos que juzgarlo exclusivamente como obra maestra de la poesía rumana, el poema Luceafărul debería ser, como cualquier creación lírica, una sublimación mediante la magia del verso de un acontecimiento de vida. Tratándose, sin embargo, de un poema de grandes proporciones, en el que se reúnen el lirismo y los elementos de cuento, de tal forma que por las virtudes de la fórmula de balada se juntan la vibración poética y la estructura épica y dramática, la cumbre de la creación de Eminescu no es el resultado de un impulso creador de momento, sino de un largo proceso creador, con etapas laboriosas, con vueltas, desarrollos y modificaciones, que se realizan a lo largo de un decenio: 18721883. La concepción unánimemente admitida es que el poema Luceafărul tiene como base otro poema original de Eminescu, de inspiración folclórica, con el título Fata în grădina de aur (La joven en el jardín de oro), cuya versificación realiza Eminescu a partir de un cuento rumano de Muntenia, cuento recogido y publicado por el alemán Richard Kunisch, en el volumen Bukarest und Stambul. Skizzen aus Ungarn, Rumänien und der Türkei, publicado en Berlín, en 1861. El cuento de Kunisch como fuente de inspiración de la más lograda creación de Eminescu es un lugar común de la crítica, empezando por Moses Gaster, Ilarie Chendi y científicamente argumentado por D. Caracostea, continuando con G. Bogdan-Duicã, G. Ibrăileanu, D.R. Mazilu, E. Lovinescu, Perpessicius, G. Călinescu, T. Vianu, D. Popovici, etc.

Esta opinión está apoyada en las mismas palabras de Eminescu, en una célebre nota descubierta por D. Caracostea en el manuscrito de una de las variantes del poema: «Mientras describe un viaje a los países rumanos, el alemán K. cuenta la leyenda del Luceafãr. Éste es el cuento. $\mathrm{Y}$ el sentido alegórico que le he conferido es que si el genio no conoce la muerte y su nombre se pierde en la noche del olvido, por otra 
parte aquí en la tierra tampoco es capaz de hacer feliz a alguien o de ser feliz. No tiene muerte, pero tampoco suerte. Me ha parecido que el destino del Luceafăr del cuento se parece mucho al destino del genio en la tierra y le he dado este sentido alegórico» (Eminescu: 1943: 4344). Especialmente esta nota ha apoyado la interpretación del poema en línea romántica, y ha llevado, según el filósofo C. Noica, a falsas interpretaciones. El argumento se encuentra en la nota misma del poeta, donde «ni rastro [...] de la imposibilidad y miseria del alma terrestre de aspirar a un ideal, sino que se trata, sensiblemente, al contrario, de la miseria de aquella naturaleza general y superior, que es su genio, en el cuento, el Luceafăr» (Noica, 1978: 99).

2.4.1. Se ha discutido mucho sobre la autenticidad del cuento de Kunisch, que no es popular, sino más bien un cuento romántico culto. La versificación eminesciana del cuento es considerada por Perpessicius como una forma anterior al poema, texto independiente de las versiones del poema propiamente dicho, entre las dos creaciones de Eminescu, habiendo una diferencia de clase, de categoría. Las evidentes diferencias de contenido y forma de la versificación nos llevan a considerar el cuento versificado como un texto independiente y no integrado en las versiones manuscritas de Luceafărul. La crítica ha gastado mucho tinta para subrayar pareceres y diferencias entre los dos textos, considerando, por supuesto, el poema en su forma definitiva. El cuento versificado Fata in grădina de aur ha sido atribuido a la época de Berlín de los estudios de Eminescu, según los manuscritos en los que ha sido incluido, y fechado en el año 1872, según Caracostea, y entre 1873-1874, según Perpessicius.

El cuento versificado por Eminescu se diferencia mucho del cuento recogido por Kunisch, del poema Luceafărul, pero sobre todo de la primera versión manuscrita de éste. Nos parece interesante un hecho no observado por los exegetas del poema, el que después de diez años de la versificación del cuento, en la tercera versión del poema, titulada $L a$ leyenda del Luceafăr, fechada el 10 de abril de 1882, Eminescu vuelve a la ternura del final de la creación anterior, radicalmente diferente, de hecho, de la cruel venganza del dragón del cuento de Kunisch. La maldición del dragón traicionado pierde la dureza de la fuente inspiradora, pero gana una ambigüedad, más allá de la comprensión mostrada: Fiți fericiț - cu glasu-i stins a spus -/Atât de fericiți cît viața toată/Un chỉn s- aveți: de-a nu muri deodată (Sed felices - les dijo con voz apagada/Tan felices toda la vida/Una sola pena tened: no muráis juntos) y en la versión del poema a la que nos referimos: Trăind porumbi împerecheți/Viața voastră toată/Un singur bine să n-aveți/Să nu muriți deo- 
dată (Viviendo como palomas emparejadas/Toda vuestra vida/Un solo bien sin alcanzar/Que no muráis juntos). Es curioso que Eminescu no haya considerado incompatible esta solución reiterada con otra variante del final, cercana a la del texto definitivo, pero mucho más estremecedora: Trăiți în cercul vostru strîmt/Și în favoarea sorții/Căci ceea ce in suflet simt/E voluptatea mortiii (Vivid en vuestro estrecho círculo/Y con la suerte favorable/Pues lo que yo siento en el alma/Es la voluptuosidad de la muerte).

2.4.2. Las versiones propiamente dichas de Luceafărul han sido ordenadas cronológicamente por el erudito Perpessicius y clasificadas, en orden: A, B, C, D, E, abarcando todo el material manuscrito y publicado del poema. A todo esto se le añade la versión $F$, la de la edición Maiorescu, ulterior a la publicada por el poeta y modificada por el crítico editor. Éstas son versiones autónomas, siendo formas surgidas en cierto momento de la realización del poema, de costumbre transcritas caligráficamente. La versión A, fechada 1880-1881, plantea a los editores y a todos los comentaristas, problemas muy difíciles, pero, según nuestra opinión, también muy importantes para el contenido filosófico y de ideas del texto integral. Es una versión incompleta, no uniforme, la primera siendo muy clara, y la segunda fragmentaria, interrumpida continuamente y repleta de sentencias y filosofías abstractas metaforizadas, que han extrañado a todos los investigadores, sobre todo a los maravillados por la aparente claridad del texto definitivo. La aparición del nombre Brahma y del tema la muerte es la madre de la vida, considerado por nosotros una referencia semántica (Marian, 1999 a) ${ }^{5}$, al igual que la relación entre la demostración desarrollada en esta auténtica lección iniciática que contiene 100 estrofas con algunos modelos de Upanişad, se puede decir que no estamos ante un carácter nebuloso y borroso, como cree Perpessicius (Eminescu, 1943: 376) y demuestra Guillermou (1977: 370), de unos fragmentos de texto que no van a ser en la forma última del poema el discurso demiúrgico, sino, todo lo contrario. Ejercida con ramificada imaginación, domina aquí la mentalidad brahmánica, en la que la eternidad del ciclo muerte-vida se conjuga con la unidad del universo y con la eter-

5 Rodica Marian, «Lumile Luceafãrului», capítulo XV; hay otros estudios dedicados a la mentalidad índica que está en la base de esta versión genuina del poema, que se centra en otras coordenadas de demostración, por ejemplo Carmen Negulei, "Variantele Luceafărului», en C. Vlad (coord.) (1992) Semiotica si poetica (5), ClujNapoca: Tipografia Universitãt,ii, 133-145; Cicerone Poghirc (1977), «O sursă indianã a Luceafărului lui Eminescu», en Caietele Eminescu, IV, București: Editura Eminescu, 50-54. 
nidad de la sustancia del mundo. Este trasfondo reflexivo pone de relieve, en última instancia, una mayor oposición, la existente entre las ambiciones inexpertas del pequeño yo y las grandes verdades de lo perenne: Tu îti atîrni de micul eu/Sperantă si durere/Te legi cu mii păreri de rău/De omul care pierell Tu crezi în stele și în sorți/Ca-n basme - a tinereții/Cînd viața biruie pe morți/Și moarte-i muma vieții. (Te aferras a tu pequeño yo/Esperanza y dolor/Te atas con mil pesares/Al hombre que fallece// Crees en astros $\mathrm{y}$ fortunas/Como en cuentos de juventud/Cuando la vida vence a los muertos/Y la muerte es la madre de la vida).

La versión B sigue de cerca a la primera; está fechada aproximadamente en el año 1881, y es la más extensa de las versiones del poema, teniendo 452 versos. Es un texto mucho más elaborado que la versión genuina, la parte fragmentaria de lo que hemos llamado «la lección iniciática» de la versión $\mathrm{A}$ se ha organizado en un discurso demiúrgico enmarcado por el vuelo del Luceafăr y por la escena final del bosque. La sustancia del debate de la lección de la versión genuina se contrae en cierto modo, pero persisten las grandes ideas de la configuración del universo de la filosofía brahmánica, la entidad llamada ahora «San Uno» sustituye a Brahma, al igual que perdura el tema del «pequeño yo» humano que no comprende la permanencia de la forma y la eternidad del alma. La unidad del universo, con su correlativo, la eternidad de la existencia, abarca también la abstracción del tiempo: «Să piară timpul înnecat/Î́n văi de întuneric/El s-ar renaște luminat/Ca să senvîrte sferic (Que muera el tiempo ahogado/En valles oscuros/Él volvería a nacer brillante/Para girar en círculos).

La versión C, titulada La leyenda del Luceafär está fechada por el poeta «abril 10-1882». Tiene una forma muy cuidada, transcrita en limpio, y con muchísimas correcciones, señal que ha sido leída y comentada quizá en las reuniones de Junimea. El debate filosófico es drásticamente reducido, codificado casi, al igual que en el texto definitivo, en versos como: «Dar piară oamenii cu toți/S-ar naște iarăși oameni»; "Un soare de s-ar stinge-n cer/S- aprinde iarăși soare»' y sobre todo «Căci toți se nasc spre a muri/Și mor spre a se naște» (Pero si murieran todos los hombres/Otros hombres nacerían; Si un sol se apagara en el cielo/Otro sol se encendería; Pues todos nacen para morir/Y mueren para nacer).

La versión D lleva la fecha 28 de octubre de 1882 y es una versión parcial, abarcando los versos 265-332, conforme a la numeración de la forma definitiva del poema. El manuscrito tiene dos columnas para- 
lelas, en una se ha transcrito la versión anterior $\mathrm{C}$, luego en las páginas de borrador se han intentado modificaciones múltiples, hasta que se llegó a las formas consideradas últimas. Encima de éstas se encuentran tachaduras a lápiz, que designan los retornos a la versión $\mathrm{C}$, lo que atesta que se ha operado la transcripción en la copia última, que ha sido enviada por el poeta a la sociedad Romînia Jună de Viena.

La versión E es la versión definitiva, la publicada en el Almanaque de la sociedad «Romînia Jună», estando fechada, según el prólogo de la revista, en abril 1883. Se han sacrificado muchas soluciones de la versión $D$, así que la versión definitiva a la que más se parece es a la versión C. La versión F, según Perpessicius, es la forma del poema en la edición Maiorescu, en cuyo texto se opera una intervención importante frente a la versión publicada por el poeta. Luceafărul está incluido en el primer volumen de poesía de Eminescu, editado por el crítico Titu Maiorescu en 1883, volumen publicado a finales de diciembre. El poema recibe dos cambios esenciales. El primero, la eliminación de cuatro estrofas, la primera de ellas la estrofa 77, en la que se concentra expresivamente, según nuestra opinión, no tanto la caducidad de las aspiraciones humanas, como el volver cíclico en la eternidad de la existencia: Ei numai doar durează-n vînt/Deșerte idealuri -/Cînd valuri află un mormînt/Răsar în urmă valuri (Ellos sólo duran en el viento/Ideales vanos -/Cuando las olas mueren/Detrás nacen otras olas). Maiorescu no ha entendido la necesidad de estas estrofas, al no tener capacidad de recepción de la sustancia del contenido de filosofía índi$\mathrm{ca}$, remanente en el texto definitivo, aunque drásticamente resumida frente a la versión A. Las siguientes tres estrofas eliminadas $(82,83$, 84) son las en que El Padre celestial le ofrece a Hyperión destinos excepcionales en las cumbres de la sabiduría, del arte y de la acción, glorias que se enfrentan al tiempo y cuadran con un genio in statu nascendi, teniendo por lo tanto, su función indudable en la formación del poema. El segundo cambio es una intervención en el texto publicado del poema durante la vida del poeta, Maiorescu sustituyendo los últimos dos versos de la estrofa 81 con unos escritos por el mismo, según Perpessicius: Tu ești din forma cea dintîi,/Ești veșnică minune (Tú eres de la forma la primera/Eres eterna maravilla). Aunque convencionales, estos versos, al igual que la arbitraria versión de Maiorescu, se han impuesto en la época por el prestigio del que los había patrocinado, siendo considerada esta versión superior a la versión publicada por el poeta en abril de 1883. Es reproducida en las ediciones más prestigiosas de poesía de Eminescu, sobre todo las anteriores a la edición académica de Perpessicius (G. Ibrăileanu, C. Botez, M. Dragomirescu, 
etc.). Los adeptos de la versión Maiorescu afirman que las modificaciones pertenecen a Eminescu, y los críticos y editores que no lo aceptan aportan argumentos convincentes a favor del texto publicado por el poeta. El primero de éstos últimos, que explica ya desde 1910 la importancia de las estrofas eliminadas por Maiorescu, es D. Caracostea $(1980,1987)$. Recientemente, P. Cretia intenta justificar de nuevo la versión Maiorescu, siendo, en su opinión, obra del mismo poeta. Sólo que la prioridad de la claridad lógica de las oposiciones entre lo humano y lo divino, en las que se basa P. Cretia (1987: 17-24; 1988: 58-60), significa una reducción drástica del contenido de ideas del poema, tal y como lo hemos mostrado (Marian, 1999a: 120-142).

2.5. El estudio de las variantes de Luceafărul en la forma editorial dada por Perpessicius, la más prestigiosa por supuesto, es, sin embargo, difícil y complicada, porque el material poético de las variantes es consignado sólo al pie de página de la versión considerada acabada en cierto momento de la génesis del poema, algunas formas y subvariantes, apareciendo incluso después de unas cuantas páginas con respecto al verso o a la estrofa llamada por Perpessicius «de la primera planta», es decir, la reproducida en la página propiamente dicha de la edición, mientras que las variantes aparecen en mayúsculas y tienen notas. La edición de Perpessicius quiere poner de manifiesto el proceso de creación de Eminescu, tanto en la búsqueda de las formas como en la cronología de las distintas etapas. Sin dejar de lado estos aspectos, nuestra edición tiende a poner de relieve, al situar las variantes de una versión en paralelo, la evolución y las transformaciones del material lingüístico y semántico, con sus relieves, con sus correcciones y retornos significativos de una variante a otra. En cierto sentido, la ausencia de las variantes, en ciertos fragmentos del texto de las versiones, es significativa, atestando la continuidad de la inspiración, la certeza de las intuiciones. Por otra parte, los fragmentos o las secciones en los que se intentan varias variantes (en la versión D la estrofa formada por los versos 317-320 tiene 17 variantes) ponen de relieve sucesivas modalidades de expresar aquellas «verdades» de la meditación del poeta que le obsesionan y le dominan en un momento preciso de la creación del poema. Incluso en este último caso, la colocación comparativa de las variantes, en columnas paralelas, sólo puede presentar ventajas.

El examen de las variantes sucesivas de Luceafărul y la labor del investigador en las modificaciones, innovaciones o correcciones, tal y como aparecen éstas en la edición de Perpessicius, se ven dificultados por las mismas intenciones del editor, al perseguir antes que nada la 
correcta transcripción de los manuscritos, en el orden cronológico de las versiones. Sin embargo, la edición de Perpessicius ha logrado contar con los elogios de la mayoría de los estudiosos, muy pocos citando otras ediciones. Por consiguiente, en nuestra edición, hemos citado varias de las notas de Perpessicius, referentes a la interpretación de los manuscritos con las variantes de Luceafărul, con el paréntesis (P). Las otras notas reflejan nuestras observaciones referentes al arreglo semántico y léxico de las variantes.

2.6. Al igual que los que han interpretado los manuscritos de Eminescu antes, sobre todo los manuscritos del poema Luceafărul, es decir, las ediciones Scurtu, Botez y D. R. Mazilu, Perpessicius se propone dilucidar el problema de la filiación de los manuscritos y el de la cronología de las versiones y, dentro de los límites del carácter mismo de su edición, «mucho más modesto», el de «presentación de los materiales-manuscritos» (Eminescu, 1943: 371). En una entrevista realizada en 1970, el gran editor precisa: «La edición crítica de los seis volúmenes de poesía de las Obras de Eminescu tiene el propósito, en primer lugar, de restituir la tabla más precisa de las variantes e, implícitamente, el proceso de ultimación del texto definitivo. [...] Las dos operaciones, aunque netamente diferenciadas, se han desarrollado permanentemente juntas» (Perpessicius, 1989: 246-247). Pero el ejemplar crítico añade, en los comentarios a las variantes de Luceafărul, estas palabras, válidas y actuales hoy día más que nunca: «Lo que no significa que no exista un gran problema con respecto a Luceafărul, por encima y más allá de sus datos primarios, que ha llamado la atención de todos nuestros investigadores, críticos literarios o estéticos y que vale la pena ser esbozado al menos, sino presentado incluso, en este lugar. [...] Vamos a reunir en un apéndice bibliográfico mínimo estos aspectos, aquí y por la fuerza de las cosas un poco abandonadas» (Eminescu, 1943: 371, s.n., R.M.). El problema de Luceafărul es el secreto mismo de su interpretación, un secreto asaltado por todos lados desde hace más de 120 años y que va a perdurar quizá incluso después de los futuros intentos de esclarecerlo.

A diferencia de las ediciones Botez y Mazilu, Perpessicius corrige los errores de filiación, que provienen «en su mayoría, por no haber considerado los elementos materiales y los caracteres gráficos de los diferentes manuscritos y, en segundo lugar, por no haber tomado en cuenta la forma de trabajar del poeta. Un borrador puede ser puesto al mismo nivel que una versión, caligráficamente trascrita y que representa un estado, una edad del poema, independientemente de si la dis- 
tancia entre las dos edades, como en los cuentos con príncipes fantásticos, puede ser mínima» (Eminescu, 1943: 371). Por lo tanto, la claridad de la edición de Perpessicius no puede ser y tampoco lo ha sido, puesta seriamente en duda en cuanto a la corrección de la transcripción y al establecimiento de la filiación de las versiones del poema, pero uno de los aspectos, «por la fuerza de las cosas» abandonados en esta monumental edición académica es la evolución del proceso creador de la lengua poética utilizada por Eminescu o del proceso de las transformaciones en el contenido semántico de los versos.

2.7. Partiendo del material de las versiones y de las variantes de éstas, tal y como están trascritas en la edición de Perpessicius, nuestra edición realiza una reordenación, reflejada en la puesta en página de todas las variantes, de tal modo que se puedan seguir comparativamente, dentro de una versión, las innovaciones, los retornos, las transformaciones léxicas y las del contenido semántico. Perpessicius ha ordenado las variantes, después de una larga investigación de los manuscritos, en cuatro versiones autónomas (A, B, C, y D), sin añadir el cuento Fata din grădina de aur (publicado en el volumen VI de la edición académica, el consagrado a la «Poesía popular») y tampoco las versiones impresas, que comenta, sin embargo, en el segundo volumen, con algunas referencias significativas, llamándolas versión $\mathrm{E}$, que es el texto publicado en el Almanaque «Romînia Jună» y reproducido en el primer volumen de la edición académica de la obra de Eminescu (Eminescu, 1939) y la versión F, es decir, el poema de la edición de Maiorescu, no reproducido en su edición por consideraciones naturales, el texto de esta edición siendo una amputación y una modificación del texto del Almanaque, tal y como lo mostramos, detalladamente, en nuestra edición.

Sobre la distinción entre variante y versión, Perpessicius precisaba, concisa y elocuentemente, en un artículo escrito en el año 1964, con motivo de la conmemoración de 75 años de la muerte de Eminescu: «Normalmente, variante es cualquier forma superada, dentro del proceso de elaboración de un poema. Cuando estas formas superadas concurren en la cristalización de un molde configurado, autónomo, dentro del mismo motivo, naturalmente, el término "versión" es preferible» (Perpessicius, 1989: 19-20). Nuestra opción para el texto poético integral ha determinado, en primer lugar, la posibilidad de presentar en orden las versiones, incluidas las impresas, excepto el cuento Fata din grădina de aur, texto que consideramos independiente de las versiones del poema Luceafărul. 
2.8. Dentro de cada versión (A, B, C, y D), Perpessicius ha situado «arriba» una forma que los manuscritos han impuesto como definitiva en cierto momento de la génesis del poema, forma a la que están subordinadas las variantes enviadas a pie de página, reproducidas en letra pequeña, al igual que las notas. Las variantes aparecen así en la parte inferior de cada página, pero en numerosos otros casos y otras variantes, en realidad subvariantes, de unas estrofas de la versión estándar, aparecen, algunas páginas más adelante, las notas, que son muy numerosas, o incluso al final de una versión, impresas en bloque, ya que su inserción en la parte inferior de las estrofas «de arriba» habría desarticulado la unidad del manuscrito en el que figuran ${ }^{6}$. Cada verso o estrofa variante es identificable como tal, según el número del verso, por lo tanto funciona como alternativa a la estrofa o al verso de la versión «de arriba». Cuando la estrofa o el verso de la versión estándar (la «de arriba») tiene más de una variante, Perpessicius consigna este hecho poniendo cifras o letras; así el lector puede rehacer el proceso de las correcciones o de las innovaciones para cada estrofa o verso por separado, si se esfuerza un poquito y es asiduo en sus investigaciones. La numeración de las versiones de la versión de arriba es, en la edición de Perpessicius, idéntica a la numeración de algunos manuscritos de Eminescu, es decir de 5 en 5 versos. Respetando la forma de trabajar del poeta, esta solución adoptada por el editor hace bastante difícil el seguimiento de las variantes.

3.1. Una primera diferencia entre nuestra edición y la de Perpessicius es la modificación de la numeración de los versos de la versión «de arriba»; el hecho de que cada verso sea numerado continuativamente en nuestra edición facilita la comparación de las variantes y ayuda en la consulta, al poder comparar el texto con las formas de las demás versiones. Por eso, si bien el número de estrofas y de versos no es idéntico de una versión a otra ${ }^{7}$, el investigador puede sorprender, según el número del verso, el momento preciso del fluir del texto en los

6 Para la forma de trabajar de Perpessicius resulta elocuente reproducir algunas ideas suyas en relación con las correcciones aportadas a la edición Mazilu en la transcripción de la segunda parte de la versión A: «Al ser un manuscrito borrador, no todas las formas merecen ser numeradas, [...] muchas veces 3 ó 4 formas se subordinan a una sola, cuyas variantes sucesivas y transitorias son. Un ejemplo: existe una estrofa que llamamos estrofa-Brahm [...] que tiene en la edición Mazilu, en la segunda variante, cuatro lugares y está numerada cuatro veces» (M. Eminescu, Opere, II, p. 373).

7 Véase el esquema con la variación del número de estrofas y versos en las sucesivas versiones del poema, situado por Perpessicius al final de sus notas, después del texto de las variantes (M. Eminescu, Opere, II, p. 454) y reproducido por nosotros también al final del texto integral, antes del Anexo. 
diferentes moldes de las versiones sucesivas. De este modo, la forma que hemos elegido para las variantes de una versión, situadas paralelamente, permite imaginar una puesta en paralelo del texto de las seis versiones del poema, en su forma estándar, la situada por Perpessicius «arriba». Las 6 columnas abarcarían por lo tanto las versiones manuscritas A, B, C, D y las dos versiones impresas. En esta visión, la importancia del texto definitivo saldría redimensionada, en el sentido de que va a aparecer como un momento de la sucesión en el tiempo de las versiones. Será fructífera la comparación del poema definitivo con la versión incompleta $\mathrm{D}$, que precede el texto publicado por el poeta en el Almanaque y en la que hay muchas transformaciones, luego desechadas, para volver a algunas formas de la versión C. Una tabla de este tipo va a presentar, sin embargo, sólo la evolución de las formas «de arriba», las consideradas por Perpessicius, según los manuscritos del poeta, como definitivas en cierto momento de la creación.

El auténtico laboratorio de trabajo en la expresión, del trabajo en busca no tanto de las formas perfectas, sino de «la palabra que expresa la verdad», lo podremos seguir en los avatares de las variantes dentro de una versión, tal y como nuestra edición los presenta, en columnas paralelas. En esta fase del trabajo, para cada versión en parte, Eminescu no ha meditado obligatoriamente en la perfección del verso o en la génesis de la imagen, sino que se ha concentrado en «la idea poética», que es «el alma», como dice el poeta. Los retornos ulteriores, de una versión a otra, atestan, además de la continuidad de la creación y lo novedoso de unas ideas poéticas insólitas, otro tipo de proceso, el del refinamiento estilístico, de la renuncia a los elementos demasiado concretos o de los considerados sobrantes. Lo que nos conduce a la constatación de que entre las variantes imperfectas de las versiones independientes vamos a encontrar las más numerosas imágenes no estilizadas formalmente, análogas a las del lirismo puro que I. Negoitescu admiraba en las póstumas eminescianas.

3.2. La intención de nuestra edición es, por lo tanto, reflejar el trabajo del poeta durante la realización de una versión, facilitando el seguimiento de las variantes con las transformaciones, cambios espontáneos y sus retornos a formas anteriores. A diferencia de la edición de Perpessicius, que, en esencia, respetamos en cuanto a la lección de los manuscritos, la novedad importante es la puesta en página de la versión y de las variantes, de tal forma que se pueda seguir comparativamente el proceso del pensamiento y de los procedimientos de expresión. La primera columna de la izquierda reproduce el texto de la 
versión situada por Perpessicius «arriba», es decir el texto más trabajado, y más cuidadosamente transcrito por el poeta en cierta etapa de creación del poema. Los versos de este texto están numerados continuativamente, por ejemplo, de 1 a 452, para la versión completa $B$, que es también la más extensa de todas las versiones manuscritas del poema. En el caso de la versión incompleta A, la numeración se ha hecho en función de la unidad de ideas de los fragmentos que la componen. En la columna segunda y en la tercera están reproducidas las variantes de los versos o de las estrofas de la primera. Estas variantes o subvariantes, como las llama Perpessicius, son las que reflejan las modificaciones léxicas y semánticas durante el trabajo, es decir, las que no se han hecho siempre de manera consciente, sino más bien siguiendo las olas o el fluir de la inspiración. Muchas veces, el contenido e incluso la expresión de estas modificaciones espontáneas e intentos son los más interesantes desde el punto de vista semántico.

Nuestra solución no es una ideal. Hemos intentado subsanar algunos defectos adoptando un artificio técnico. Cuando la edición académica consigna un número de variantes superior a 3 , hemos situado debajo de la primera columna, cuyos versos están numerados, otra columna, que debe ser considerada la cuarta, a la que siguen, en orden, de izquierda a derecha, la quinta columna y la sexta. Para marcar el hecho de que se pasa a la cuarta variante del verso numerado en la primera columna hemos vuelto a numerar el verso respectivo con el mismo número que el verso de la primera columna. Es más, con el fin de señalar la continuación de las variantes, cuando aparece de nuevo la numeración, hemos puesto debajo de la estrofa o del verso que tiene más de tres variantes, el signo $\rightarrow$. El mismo signo aparece también en los casos más raros, cuando las variantes no caben en la segunda línea, es decir, en los casos en los que el verso tiene una séptima variante. Después de éste, siguen, en orden, de izquierda a derecha, las variantes octava y novena. Prácticamente, con la repetición del signo $\rightarrow$, que advierte que las variantes continúan, aparece en el margen de la izquierda también la numeración de los versos. Intentamos dar una imagen esquemática mínima de la puesta en página de las variantes, según su número de orden arbitrario, que de hecho no tiene importancia ni para la lectura, ni para la profundización del contenido de ideas, al ser una simple convención que muestra que el poeta ha pensado detenidamente en algún concepto o en cierta imagen o ha vacilado a la hora de encontrar la forma. Por lo tanto, el orden y el número de columna en la que aparecen las variantes no muestran de manera expresiva o axiológica su valor, sino que es una simple ordenación del material poético hallado 
en los manuscritos. El esquema de la puesta en página de las variantes es el siguiente:

\author{
[1] [2] [3] \\ [4] [5] [6] \\ [7] [8] [9], etc.
}

Los casos muy raros en los que los versos de la versión de «arriba», la primera de la izquierda en nuestra edición, tienen más de nueve variantes, se resuelven siguiendo el mismo procedimiento, es decir volviendo a numerar e introduciendo el signo de continuación: $\rightarrow$.

3.3. Otra modificación importante, frente a la edición de Perpessicius es la introducción en la primera columna de la izquierda, es decir, «arriba», de unos versos o estrofas que no tenían esta consideración en la edición académica. Estas estrofas, consideradas como variantes por Perpessicius, merecen una especial atención, aunque hayan sido excluidas por el poeta de la versión copiada. Muestran que, en una fase anterior, se ha trabajado una idea, muy pronto sacrificada por el poeta. El lector es, por lo tanto, incitado a buscar y encontrar así esos primeros elementos sobrantes y eliminados por el poeta, pero que contienen, a veces, las más interesantes sugerencias con respecto a la inspiración y a la idea poética primaria. Las estrofas añadidas a la edición de Perpessicius, se han incorporado en la columna de la izquierda y pueden ser identificadas por la numeración de los versos anteriores a ellas, añadiendo $a$. Así, la estrofa 305a-308a está incluida, en la versión $\mathrm{B}$, antes de la primera estrofa del requirimiento del Luceafãr, y contiene el primer pensamiento del poeta en la formulación de la oración hacia El Padre. La estrofa no es una cualquiera, teniendo además unas cuantas variantes: Al cărui unic nume sfint/Nu-l știe nici o limbă,/Te rog, în mînă de pămînt/Ființa mea o schimbă (Á ti, cuyo único nombre santo/Desconocen todas las lenguas/Te pido, en mano de tierra/Cambia mi ser). Frente a la discreción del texto definitivo, en el que la instancia invocada por el Luceafär es sólo un padre y Señor, estos versos aportan informaciones valiosas, el «único nombre santo», siendo sustituido en la variante por «único signo», lo que está repleto de significaciones.

Resultan muy interesantes las situaciones que aparecen señaladas en el corpus de la edición con los dos signos, es decir, tanto con el signo 
de continuación de las variantes $(\rightarrow)$, como con el que atesta una estrofa inexistente en la versión considerada estándar por Perpessicius, es decir, la de la izquierda, situaciones marcadas con: $\rightarrow \rightarrow$. Este tipo de situaciones son menos frecuentes, pero no por ello menos importantes, ya que muestran el lugar en el que, a menudo inesperadamente, se concentra la tenacidad y el trabajo creador del poeta. Dicho de otra manera, tenemos señalados de esta forma aquellos «núcleos de poeticidad». Mencionamos aquí sólo un ejemplo, edificador para alguien que va a estudiar la poeticidad de la «nada» en el texto poético integral. En la versión B, la estrofa 293-296 tiene cuatro cambios de numeración, lo que significa que ha tenido 12 variantes, de las que una ha sido considerada como la versión definitiva en cierto momento de la génesis del poema. De las 12 variantes, 6 son de la estrofa 293a-296a, que no aparece en la versión estándar: Aci vecia a-ncetat/Să se-nvîrtească sferic,/Virgin de raze și păcat/Se - tinde intuneric (Aquí la eternidad cesó/De girar en círculo/Sin rayos ni pecado/Se extiende la oscuridad). Vemos, de manera inmediata y explícita, cómo el poeta concibe la nada como una superación de la visión circular del tiempo. Tampoco faltan las implicaciones de extracción filosófica que pueden asociar la oscuridad con adăpostul stingerii (la guarida de la muerte) o al păcii (de la paz) de otras variantes. Otro ejemplo encontramos en la misma versión $B$, en el momento textual del comienzo del vuelo del Luceafăr. La versión de «arriba», es decir, la numerada por nosotros, abarca este fragmento en 26 versos (de 277 a 293). Las columnas paralelas de las variantes cuentan más de 100 versos, lo que habla de por sí del esfuerzo gigantesco del poeta para sorprender en imágenes la gran aventura del Luceafăr. El caso más elocuente es el de la estrofa 317-320 de la versión $\mathrm{D}$, en el que algunos versos tienen 17 variantes; la estrofa está excluida de la versión definitiva $(\mathrm{E})$, su desaparición haciendo hermética la naturaleza de la hipóstasis textual llamada Hyperión. Se puede seguir en la lectura de estas variantes el esfuerzo del poeta por esbozar la verdad abstracta acerca del no creado Hyperión, congénere del Padre celestial, al igual que las motivaciones profundas de la imposibilidad, a causa de su condición, de recibir vida y muerte: Cum ai putea să fii zidit/Din lacrimi și din vină -/Cînd ești din veci nerăsărit/Lumină din lumină (Cómo podrías estar hecho/De lágrimas y culpas-/Cuando por la eternidad engendrado/Luz de luz) o, más explícito todavía: Cum ai putea sa fii supus/Să porți a vieții vină,/Făr 'de apus ai răsărit/Lumină din lumină (Cómo podrías estar sometido/A llevar la culpa de la vida/Naciste sin ocaso/Luz de luz). 


\section{Referencias bibliográficas}

AsHeR, N. (1996). «L'interface pragmatique-sémantique et l'interprétation du discours». Langages 123.

Bajtín, M. (1982). Probleme de literatură și estetică. Traducción al rumano. Bucuresti: Univers.

BlagA, L. (1968). Mahatma Gandhi asa cum l-am cunoscut. Secolul XX 2, 217-229.

BELlemin-NoËL, J. (1972). Le texte et l'avant-texte. Paris: Larousse.

BORCILĂ, M. y MCLAIN, R. (eds.) (1981). Poetica americană. Orientări actuale. Cluj-Napoca: Dacia.

BulgăR, Gh. (1980). M. Eminescu. Coordonate istorice și stilistice ale creatiei. Iași: Junimea.

CARAcostea, D. (1980). Arta cuvîntului la Eminescu. Iași: Junimea.

- (1987). Creativitatea eminescianã. Iasi: Junimea.

Cimpoi, M. (1999). Plînsul demiurgului. Ias,i: Junimea.

Constantinescu, P. (1987). O catedrã Eminescu. Ias,i: Junimea.

CORTI, M. (1978). Il viaggio testuale. Le ideologie e le strutture semiotiche. Torino: Einaudi.

CoteAnu, I. (1985). Stilistica functională a limbii române. Vol. II. Limbajul poeziei culte. Bucuresti: Editura Academiei .

CrețiA, P. (1987). «Editarea operei poetice a lui Eminescu. Bilant,ul unui veac», VII. Viata Românească LXXXII, 17-24.

- (1991). «Un' nou dar al manuscriselor eminesciene». En Manuscriptum. Număr special: Eminescu, anul XXII, 1.

Dictionarul limbii poetice a lui Eminescu (1968). Bucuresti: Editura Academiei (bajo la coordinación del académico T. Vianu).

DuCROT, O. (1984). Le dit et le dire. Paris: Minuit.

Ducrot, O. y Todorov, T. (1972). Dictionnaire encyclopédique des sciences du langage. Paris: Seuil.

EMINESCu, M. (1939). Opere I, Poezii tipărite în timpul vieții. Introducere. Note și variante. Anexe, 167-181. Edición crítica a cargo de Perpessicius. Bucuresti: Fundaţia Regală pentru Cultură și Artă.

- (1943). Opere, II. Poezii tipărite în timpul vieții. Note și variante: de la Povestea codrului la Luceafărul, 370-455. Edición crítica a cargo de Perpessicius. București: Fundat,ia Regală pentru Cultură și Artă.

- (1977). Literatura populară. București: Editura Cartea Românească.

GáldI, L. (1965). Stilul poetic al lui Mihai Eminescu. București: Editura Academiei .

Genette, G. (1982). Palimpsestes. La littérature au second degré. Paris: Seuil.

GHEȚIE, I. y MARES A. L. (1974). Introducere în filologia românească. Probleme. Metode. Interpretări. București: Editura enciclopedică română. 
GOLOPENTIA-ERETESCU, S. (1978). «Analiză contrastivă și semiotică». SCL XXIX, 1, 3-17.

Greimas, A. J. y CourTés J. (1979, 1984). Sémiotique. Dictionnaire raisonné de la théorie du langage, I, II. Paris: Larousse.

GRouPE M. U. (1977). Rhétorique de la poésie. Bruxelles: Complexe.

Gulllermou, A. (1977). Geneza interioară a poeziilor lui Eminescu. Iași: Junimea.

MARIAN, R. (1999a). «Lumile» Luceafărului. Cluj-Napoca: Remus.

- (1999b). Mihai Eminescu, "Luceafărul». Text poetic integral. Edición crítica, introducción, notas y comentarios. Cluj-Napoca: Remus.

MARIAN, R. y ȘERBAN F. (2000). Dicționarul Luceafărului eminescian. ClujNapoca: Clusium.

Mavrodin, I. (1982). Poietică și poetică. București: Univers.

MoesChler, J. y Reboul, A. (1999). Dicționar enciclopedic de Pragmatică. (traducción al rumano, coord. C. Vlad, L. Pop). Cluj: Echinox.

MORRIS, Ch. (1938). «Foundation of the Theory of Signs». International Encyclopedia of Unified Sciences. Erkenntnis, vol. VIII, 131-150.

NegorŢESCU, I. (1980). Poezia lui Eminescu. Iasi: Junimea.

NegulEI, C. (1992). «Variantele Luceafărului». En C. Vlad (coord.), Semiotica si poetica (5) 133-145. Cluj-Napoca: Tipografia Universitătii.

NET, M. (1992). "Cîteva observații cu privire la simbolul "socio-cultural"». En C. Vlad (ed.), Semiotica și poetica (5), 240-246. Cluj-Napoca: Tipografia Universității.

NET,, M. (2000). Eminescu altfel. Limbajul poetic eminescian. O perspectivă semiotică. Bucuresti: Minerva.

Niculescu, A. (1980). «Text poetic». En M. Borcilă (ed.), Studii de stilistică, poetică, semiotică, 143-144. Cluj-Napoca: Tipografia Universitat,ii.

NorcA, C. (1978). Sentimentul românesc al fiintei. București: Eminescu.

OANCEA, I. (1998). Semiostilistica. Timisoara: Excelsior.

PERPESSICIUS (1989). Eminesciana II. Bucuresti: Minerva.

PoghiRC, C. (1977). «O sursă indiană a Luceafărului lui Eminescu». Caietele Eminescu IV, Bucuresti, 50-54.

SchміDт, S. J. (1973). Texttheorie. Probleme einer Linguistik der sprachlichen Kommunikation. München: Fink.

UsCĂTESCU, G. (1968). Nou itinerar. Madrid: Taurus.

VALERY, P. (1938). Introduction à la poétique. Paris: Gallimard.

VLAD, C. (1982). Semiotica criticii literare. București: Editura științifică și enciclopedică.

- (2000). Textul aisberg. Cluj: Casa Cărții de Știință. 